\title{
CAPITAL HUMANO RURAL E PRODUTIVIDADE AGRÍCOLA: ANÁLISE ESPACIAL PARA A REGIÃO SUL DO BRASIL
}

\author{
Amarildo de Paula Junior ${ }^{1}$ \\ George Lucas Máximo ${ }^{2}$
}

\begin{abstract}
RESUMO
O aumento da capacidade técnica, via educação, eleva a produtividade no trabalho, independente de qual seja o setor em que o indivíduo esteja empregado, conforme Schultz (1961). Diante disso, o presente artigo tem como objetivo analisar a correlação espacial entre o capital humano rural e a produtividade de produtos agrícolas que estão entre os mais cultivados na região Sul: milho, trigo e soja. Os dados utilizados neste estudo são do Censo Agropecuário e da Pesquisa Agrícola Municipal (PAM), ambos para o ano de 2017. A abordagem estatística aplicada neste estudo é a de Análise Exploratória de Dados Espaciais (AEDE), em que é possível analisar as correlações entre variáveis no espaço. Os resultados encontrados apontam para uma correlação global positiva entre capital humano rural e produtividade agrícola. $\mathrm{Na}$ desagregação entre culturas, a análise local demonstrou que as distribuições dos clusters são semelhantes, embora haja uma ligeira dissemelhança no sul do Rio Grande do Sul.
\end{abstract}

Palavras-Chave: Capital humano rural, produtividade agrícola, região sul.

\section{RURAL HUMAN CAPITAL AND AGRICULTURAL PRODUCTIVITY: SPATIAL ANALYSIS FOR SOUTH BRAZIL REGION}

\begin{abstract}
The increase in technical capacity via education increases productivity at work regardless of the sector in which the individual is employed according to Schultz (1961). In view of this this article aims to analyze the spatial correlation between rural human capital and the productivity of agricultural products that are among the most cultivated in the Southern region: maize, wheat and soy. The data used in this study are from the Agricultural Census and Municipal Agricultural Research (PAM) both for the year 2017. The statistical approach applied in this study is the Exploratory Analysis of Spatial Data (AEDE) in which it is possible to analyze the correlations between variables in space. The results found point to a positive global correlation between rural human capital and agricultural productivity. In the disaggregation between cultures the local analysis showed that the distributions of the clusters are similar although there is a slight dissimilarity in the south of Rio Grande do Sul.
\end{abstract}

\begin{tabular}{|c|c|c|c|c|c|}
\hline $\begin{array}{l}\text { Graduado em Economia } \\
\text { amarildojunior.eco@gmail.com }\end{array}$ & (UNIFCV). & Mestrado & em & Economia & (PCE-UEM). \\
\hline $\begin{array}{l}\text { Graduado em Economia } \\
\text { yeorgeemaximo@gmail.com }\end{array}$ & (UNIVILLE). & Mestrado & em & Economia & (PCE-UEM). \\
\hline
\end{tabular}


Keywords: Rural human capital, agricultural productivity, south region. JEL Code: E24, O13

\section{INTRODUÇÃO}

O agronegócio brasileiro tem parcela relevante no produto interno bruto do país, de acordo com o Centro de Estudos Avançados em Economia Aplicada - CEPEA (2017), o setor representou $21,6 \%$ do PIB total do país denotando a magnitude da importância do setor para a economia nacional. Neste setor que é heterogêneo em culturas ao longo do território nacional, a região Sul tem certo destaque e relevância para o setor. Isso posto, porque apesar da região ser a menor do país em expansão territorial ela possui uma das maiores produtividades agrícolas segundo 0 Levantamento Sistemático da Produção Agrícola - LSPA (2017).

Os principais cultivos da região Sul são: milho, soja e trigo. Sendo que, as duas primeiras são as principais culturas de verão e a última se destaca como cultura de inverno (STRECK; ALBERTO, 2006). No ano de 2017 as três culturas em conjunto corresponderam a cerca de $86 \%$ do total da produção agrícola na região Sul (LSPA, 2017). Além disso, essas culturas possuem elevado rendimento médio na região, o quilograma produzido por hectare plantado nessas culturas é maior do que em culturas como o algodão e o feijão.

Por sua vez, o avanço de tecnologias utilizadas nas lavouras e sua relação positiva com o elevado nível de capital humano na construção destas faz com que as zonas rurais demandem força de trabalho capacitada tecnicamente para o manejo dessas tecnologias da maneira mais eficiente possível. $\mathrm{O}$ alto nível técnico nas zonas rurais eleva a produtividade com a melhor utilização do espaço e de equipamentos mesmo se estes recursos forem limitados (LOCKHEED et al., 1980; BINSWANGER, 1986).

Além disso, Mendes e Pereira (2009), reiteram que a educação inserida no meio rural é uma ferramenta para introduzir conhecimento e habilidades e sobretudo transformar a realidade da economia de subsistência das zonas rurais em uma economia mais desenvolvida e moderna denominado de tecnificação da agricultura.

O efeito do aumento da educação do agricultor pode melhorar a qualidade do componente trabalho definido como a capacidade de produzir mais fornecidas as mesmas condições e quantidades de insumos, além de que também influencia na capacidade em adquirir e analisar informações para elaborar planos de tomadas de decisões sobre qual o melhor insumo e ou melhor cultivar a ser manejado para determinadas condições edafoclimáticas (PATRICK e KEHRBERG, 1973).

Outro estudo sobre a relação entre produtividade agrícola e nível de escolaridade é o de Vicente, Anefalos e Caser (2003), no qual os autores mediram a influência do capital humano sobre a produtividade total dos fatores da agricultura durante o final do século XX. Os resultados de pesquisa apontaram para uma relação positiva entre capital humano e produtividade agrícola já naquela época.

Compreendida a importância do agronegócio da região Sul para a economia brasileira e também a relevância do nível de capacitação técnica para a produtividade deste setor, o presente estudo tem como objetivo analisar a relação entre capital humano e produtividade dos principais cultivos agrícolas da região Sul: milho, soja e trigo. A análise é feita por meio da Análise Exploratória de Dados Espaciais - AEDE com dados do Censo Agropecuário e da Pesquisa Agrícola Municipal - PAM para o ano de 2017.

Sendo assim, o estudo está estruturado em cinco seções, além desta introdução, a seção 2 trata da revisão da literatura sobre o tema. A seção 3 apresenta 
a estatística descritiva dos dados e abordagem metodológica. A seção 4 apresenta a análise os resultados obtidos e, por fim, a última seção corresponde às principais conclusões do artigo.

\section{REVISÃO DE LITERATURA}

A partir de 1950 com o fim da segunda guerra mundial as pesquisas acerca do capital humano obtiveram um novo marco com os trabalhos seminais de Theodore Schultz, Gary Becker $(1962,1964)$ e Jacob Mincer $(1958,1962)$, da Universidade de Chicago. Blaug (1992), descreve o surgimento da Teoria do Capital Humano por meio de Theodore Schultz, o qual incute no seu programa de pesquisa a ideia de que o indivíduo investe em si mesmo de maneiras distintas buscando desfrutar sua situação presente e pensando em rendimentos futuros sejam eles pecuniários ou não, isto é, objetivando auferir ganhos em dinheiro ou não (MONTEIRO, 2016).

Há influências no trabalho de Blaug (1986), acerca das origens da discussão sobre o capital humano em Adam Smith (1776), Alfred Marshall (1890) e nos estudos de Irving Fisher que teria utilizado a Teoria do Capital de Walras e a teria exposto conforme afirma Monteiro (2016), em 1906 no seu livro The Nature of Capital and Income.

As pesquisas de Schultz sobre a agricultura e desenvolvimento a qual inseria a ideia de investimento em educação humana no centro da problematização pode ter suas origens na experiência obtida do pós-guerra, quando este fazia parte da Comissão que oferecia suporte aos planos de reconstrução da Alemanha Ocidental. Nessa posição ele observou em primeira mão os efeitos da destruição do estoque de capital físico da Alemanha e sua posterior reconstrução. Essa visão Ihe proporcionou traduzir a superação de obstáculos produtivos por meio da educação dos agentes econômicos (MONTEIRO, 2016).

Portanto, Schultz (1967) atribui ao fator mão de obra um peso maior, assim o indivíduo que investir na obtenção do conhecimento passa a ter maiores rendimentos e possível deslocamento na pirâmide social. Os detentores do capital humano são os próprios indivíduos, os quais não podem se separar de suas habilidades e quanto maior conhecimento adquirirem, maior será a produtividade.

Dessa forma, o trabalhador possui incentivos a continuar sua busca por educação com a expectativa de retornos tornando a educação em um ativo de negociação.

Schultz (1975), Becker (1993) e Huffman (1998), apontam para a existência de evidências em que o nível de escolaridade dos empreendedores se torna uma habilidade ou recurso valioso quando a tecnologia está em curso de mudanças, isto é, quando a agricultura passa por uma transição dos métodos tradicionais para métodos mais disruptivos e modernos, enfatizando a importância dos investimentos em capacitação da mão de obra e em especifico quando direcionado para a agricultura.

A construção ou transferência desse conhecimento pode ocorrer por meios formais ou informais. Huffman (2000), descreve que pode ser obtido por meio da experiência dos agricultores, inovações mecânicas desses agricultores, instituições formais especializadas no desenvolvimento e transferência desse conhecimento como em centros Universitários e institutos de pesquisa. As pesquisas institucionalizadas para ser bem-sucedida demandam ciência, na qual é recebido investimentos financeiros e intelectuais desenvolvidos por meio de uma carga intensa de treinamento. 
Para Huffman (2000), a criação e o uso de ferramentas para o trabalho é frequentemente o objetivo das escolas formais, ou seja, um caminho institucionalizado. Sendo que a educação é considerada a mais importante forma de capital humano e os canais formais para obtenção e desenvolvimento dessa busca por conhecimento ocorrem principalmente em: escolas primárias, secundárias e universidades. A criação de habilidades úteis para o desempenho no trabalho se forma não somente com a escolaridade, mas se inicia cedo antes mesmo da formação educacional formal do indivíduo.

Essa estruturação da formação e desenvolvimento da busca pelo conhecimento por meio dos canais formais em institutos de pesquisa e Universidades tem sido a fonte de novas tecnologias como produtos químicos para a lavoura, técnicas modernas de controle de pragas, produtos farmacêuticos e novos maquinários, provocando uma elevação no nível de mecanização no campo e gerando aumentos na produtividade agrícola tendo por exemplo, a automatização e intensificação no preparo da área a ser cultivada (HUFFMAN, 2000; HUFFMAN e EVENSON, 2001).

Diante do exposto, a adoção de tecnologias de informação baseadas em coleta e análise de dados, em que se utilizam de computadores, sensores e satélites com avançadas possibilidades de medição sobre os aspectos climatológicos e ambientais, permite ao produtor agrícola maior assertividade nas suas escolhas, como por exemplo, qual cultivar plantar, qual defensivo agrícola aplicar, e por sua vez, fornece informações cujo teor pode ser usado no gerenciamento de risco de preço, como assumir uma posição contrária no mercado futuro por meio de estratégias de hedge considerando possíveis variações abruptas nos preços (MARQUES, 2006).

Além disso, o produtor rural moderno demanda relativamente mais tempo planejando, analisando e gerenciando seus empreendimentos agrícolas e menos tempo em campo do que o fazia em meados do século passado. Dessa forma, a aquisição de informações, a capacidade de refinar e analisar essas informações para serem utilizadas na tomada de decisões exige cada vez altos níveis de escolaridade (HUFFMAN e EVENSON, 2001; PONTES e MAIA, 2017).

Entretanto, um desafio está se formando na agricultura a qual vem revelando um declínio progressivo na participação do PIB em todo o mundo conforme relata Kumar et al. (2014), cujos achados de pesquisa apontaram as rápidas mudanças ocasionadas pelo progresso tecnológico, bem como por meio da adoção de equipamentos mais potentes e versáteis e pela financeirização do mercado agrícola demandando maior orientação para o mercado, competitividade e produtividade. Com a inserção de novos agentes na dinâmica da economia agrícola vem se formando uma mudança de paradigmas nos padrões de emprego e demanda de emprego dos graduados na área do agronegócio (KUMAR et al., 2014; BINSWANGER, 1986; HUFFMAN e EVENSON, 2001).

Tendo em vista as mudanças na globalização e desenvolvimento de novas tecnologias, Kumar et al. (2014), apelam para uma mudança na formação curricular do corpo técnico envolvido nas fases do agronegócio, afirmando que os graduados nessa área não tenham somente os conhecimentos técnicos, mas também, habilidades empreendedoras, e conhecimentos mais específicos nos campos da biotecnologia e do direito.

John Mellor (1963) sublinha que todas as características envolvidas no crescimento agrícola através das mudanças tecnológicas são baseadas na expansão da rede de abrangência institucional voltadas ao apoio rural por meio do ensino e capacitação para beneficiar o produtor de pequeno porte que é um indivíduo importantíssimo para a estratégia de alto desempenho da economia agrícola. Contudo, devido a extensa área de cobertura do setor agrícola se requer uma 
quantidade massiva do uso de mão de obra treinada, dessa forma a ênfase no desenvolvimento rural demanda um expressivo esforço em investimentos para expandir a educação em todos os níveis gerando a mão de obra demandada.

Lockheed et al. (1980) utilizaram 37 conjuntos de dados, cuja abrangência foi realizada em 18 estudos sobre educação e produção agrícola de 13 países da África, Ásia, Europa e America Latina, incluindo o Brasil. Deste total de estudos, em boa parte dos conjuntos de dados foram verificados os efeitos da educação sobre a eficiência técnica na produção de cereais como o arroz, trigo e o milho, nos casos restantes foram analisados culturas mistas, como, bananas, algodão, vegetais e canade-açúcar.

Dessa forma, a hipótese de que a educação dos agricultores teria um efeito positivo sobre a sua eficiência foi confirmada, ou seja, encontrou-se significância estatística em 31 conjuntos de dados de 37. Para cada ano adicional de educação ocorreria um aumento percentual na produção, isto é, em sua variação de crescimento. Por outro lado, para os seis casos contrários o efeito foi não significativo. Os resultados de pesquisa indicam que a produtividade agrícola aumenta em média $7,4 \%$ em resposta ao acréscimo de 4 anos adicionais de ensino fundamental ao invés de nenhum, corroborando com a hipótese de Schultz de que a eficiência é aprimorada em um ambiente em constante atualização (LOCKHEED et al., 1980).

\section{DADOS E MÉTODO}

\subsection{ESTATÍSTICA DESCRITIVA DOS DADOS}

Os dados utilizados nesta pesquisa são para o ano de 2017 e foram retirados do Censo Agropecuário e da PAM, ambas fontes são do Instituto Brasileiro de Geografia e Estatística - IBGE.

O Quadro 1 apresenta as variáveis utilizadas neste estudo, sendo que, as culturas foram selecionadas pela frequência de cultivo na região Sul de acordo com o LSPA (2017).

A justificativa pela escolha de uma variável relacionada a educação formal é que, embora o capital humano seja mais abrangente do que basicamente anos de estudo ou titulação, a variável $\mathrm{CH}$ Rural capta o efeito necessário para verificar em âmbito rural se o estoque deste capital é positivamente relacionado no espaço com a produtividade agrícola.

Quadro 1 - Apresentação das variáveis.

\begin{tabular}{|l|l|}
\hline Variáveis & Descrição \\
\hline CH Rural & $\begin{array}{l}\text { Nível de capital humano rural, representado pelo número de proprietários ou } \\
\text { arrendatários de terras que concluíram o ensino superior a cada mil habitantes. }\end{array}$ \\
\hline PMilho & $\begin{array}{l}\text { Produtividade do cultivo de milho, representado pela razão entre a quilograma } \\
\text { produzida e o hectare plantado. }\end{array}$ \\
\hline PSoja & $\begin{array}{l}\text { Produtividade do cultivo de soja, representado pela razão entre a quilograma } \\
\text { produzida e o hectare plantado. }\end{array}$ \\
\hline PTrigo & $\begin{array}{l}\text { Produtividade do cultivo de trigo, representado pela razão entre a quilograma } \\
\text { produzida e o hectare plantado. }\end{array}$ \\
\hline PCulturas & $\begin{array}{l}\text { Produtividade média das culturas analisadas, representado pela razão entre a } \\
\text { quilograma produzida e o hectare plantado. }\end{array}$ \\
\hline
\end{tabular}

Fonte: Censo Agropecuário e PAM. 
Por meio de uma análise comparativa entre os estados apresentada pelas médias das variáveis por estado na Tabela 1, observa-se que o estado que possui maior nível de capital humano rural é o Rio Grande do Sul. O Paraná possui a maior produtividade no cultivo de soja, de trigo e da média das três culturas. No caso da produtividade do cultivo de milho, o estado que lidera este quesito é Santa Catarina.

Tabela 1 - Média das variáveis por estado e na região Sul

\begin{tabular}{lcccc}
\hline Variáveis & PR & SC & RS & Sul \\
\hline CH Rural & 5,16 & 4,59 & 5,36 & 5,11 \\
PMilho & 6.200 & 6.836 & 6.541 & 6.499 \\
PSoja & 3.355 & 2.208 & 2.853 & 2.864 \\
PTrigo & 1.787 & 1.134 & 1.224 & 1.391 \\
PCulturas & 3.780 & 3.393 & 3.537 & 3.583 \\
\hline
\end{tabular}

Fonte: Censo Agropecuário e PAM.

$\mathrm{Na}$ distribuição espacial das variáveis utilizadas apresentada na Figura 1, verifica-se que as maiores concentrações de $\mathrm{CH}$ Rural acontecem em alguns pontos do norte do Paraná, do sul de Santa Catarina, do oeste e do sul do Rio Grande do Sul. Em relação à produtividade das culturas analisadas, pode-se afirmar que os pontos da região Sul que possuem as maiores concentrações estão entre o centro do Paraná e o norte do Rio Grande do Sul.

Além disso, Araújo (2012), analisou os efeitos provocados por oscilações nas quantidades de precipitação e temperatura sobre a produtividade das lavouras de cana-de-açúcar, arroz, feijão, trigo, milho e mandioca para as regiões Nordeste e Sul do Brasil. Utilizando regressões em painel o autor estimou que o Rio Grande do Sul é significativamente impactado por variações abruptas no clima, o que pode corroborar com as variáveis explanatórias disponíveis nesta pesquisa sobre as variações na produtividade dos cultivares.

A produtividade mais abrangente entre as culturas é a de soja, visto que ela se sobressai no extremo noroeste do Paraná e no extremo sul do Rio Grande do Sul, enquanto a produtividade do milho e do trigo não possuem este comportamento. 
Figura 1 - Distribuição espacial das variáveis

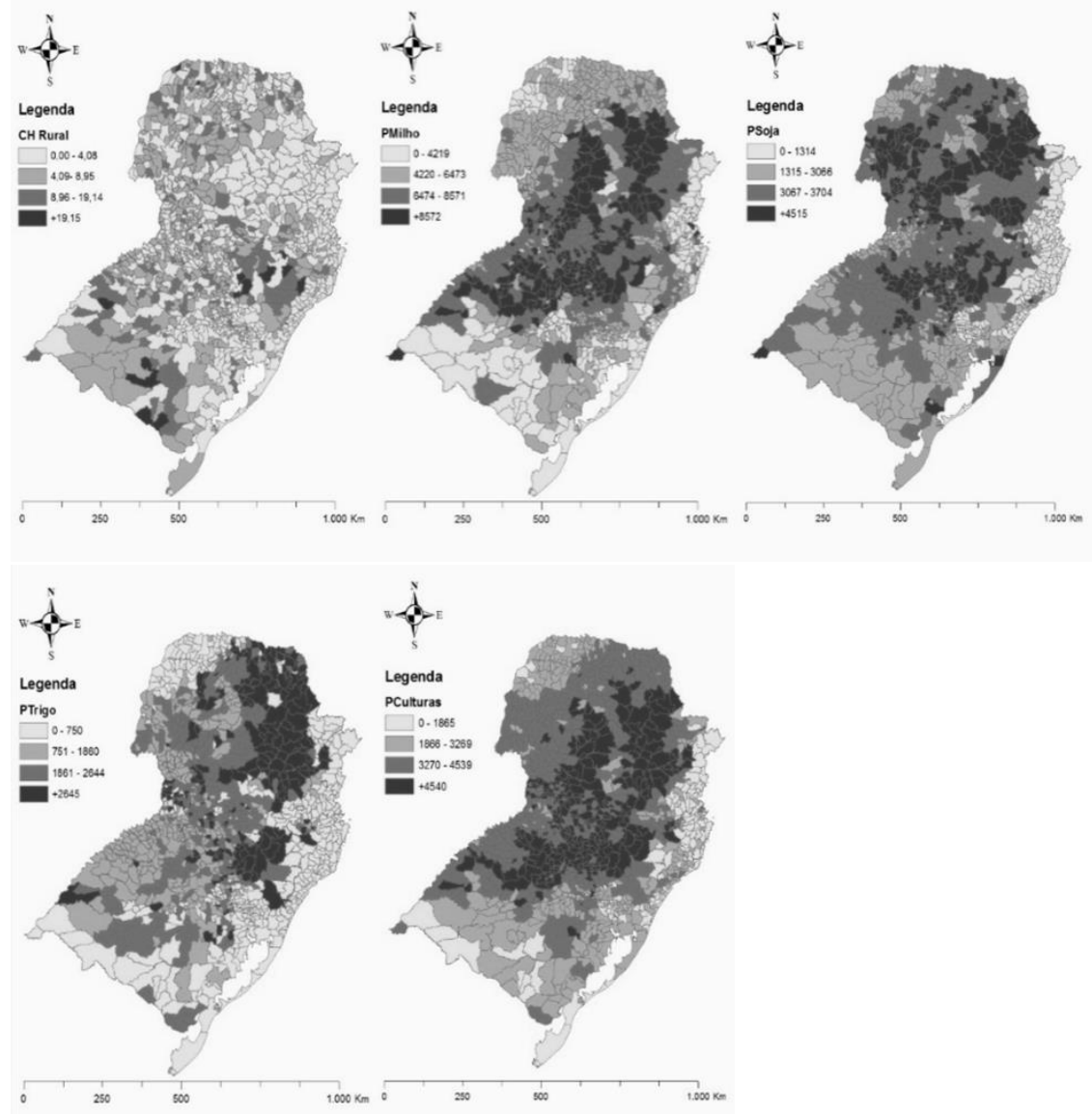

Fonte: Elaborado pelos autores (2020)

\subsection{ABORDAGEM METODOLÓGICA}

A Análise Exploratória de Dados Espaciais é utilizada para verificar se os dados possuem algum tipo de correlação no espaço, e para isso é aplicado o teste de I de Moran. Este método estatístico fornece a relação entre observações de uma determinada variável com a média das ponderada dos valores da vizinhança (ALMEIDA; PEROBELLI; FERREIRA, 2008). Na análise global multivariada o I de Moran é expresso da seguinte maneira:

$$
I_{t}=\left(\frac{n}{S_{0}}\right)\left(\frac{z_{1}{ }^{\prime} W z_{2}}{z_{1}{ }^{\prime} z_{1}}\right)
$$

em que $z$ é um vetor com $n$ observações na forma de erro em relação à média. $W$ representa a matriz de pesos espaciais, que geralmente é escolhida entre torre, rainha e $k$ vizinhos, sua escolha se dá pelo maior I de Moran calculado e significativo. $S_{0}$ representa o somatório de todos os elementos que compõe a matriz 
W (ALMEIDA, 2012). Quando a matriz de pesos está normalizada o I de Moran para análise global multivariada é expresso como:

$$
I_{t}=\left(\frac{z_{1}{ }^{\prime} W z_{2}}{z_{1}{ }^{\prime} z_{1}}\right)
$$

Além da análise global é possível verificar as correlações espaciais localmente. Essa análise de correlação espacial é feita com o Local Indicators of Spatial Association (LISA) que de acordo com Anselin (1995), é uma técnica que consiste em rejeitar ou não a hipótese nula de ausência de correlação espacial local. O I de Moran para análise LISA bivariada é apresentado da seguinte maneira:

$$
I_{i}=z_{1 i} W z_{2 i}
$$

Em que, $W z_{2 i}$ é a defasagem espacial de $W z$. Após a aplicação da análise LISA, verifica-se a presença de clusters espaciais. Segundo Almeida (2012), os clusters podem ser divididos em 4 formas: Alto-Alto, Baixo-Baixo, Baixo-Alto e AltoBaixo. Para a análise local multivariada a primeira forma indica que as unidades espaciais nos clusters exibem altos valores em uma variável de interesse e são rodeados por unidades que possuem altos valores em outra variável. Na segunda forma, ocorre o inverso, as unidades espaciais nos clusters exibem baixos valores em uma variável de interesse e são rodeados por unidades que possuem baixos valores em outra variável. Na terceira forma, são baixos valores para uma variável de interesse e altos valores para outra variável. E por último, valores altos para a variável de interesse e baixos valores para outra variável.

\section{RESULTADOS}

$\mathrm{Na}$ Tabela 2 são apresentadas a escolha da matriz de pesos que será utilizada nesta pesquisa, observa-se que a matriz que possuiu o maior I de Moran significativo é a matriz Rainha. Visto que para a escolha da matriz é feita a estatística I de Moran univariada global, desde então é possível verificar que há uma correlação espacial positiva entre $\mathrm{CH}$ Rural do município $i$ com o $\mathrm{CH}$ Rural do município $j$, já que I de Moran Calculado > I de Moran Esperado.

Tabela 2 - Escolha da matriz de pesos

\begin{tabular}{lccc}
\hline Matriz & I de Moran Calculado & I de Moran Esperado & P-Valor \\
\hline Rainha & 0,269 & $-0,0008$ & 0,001 \\
Torre & 0,268 & $-0,0008$ & 0,001 \\
K-5 & 0,261 & $-0,0008$ & 0,001 \\
K-7 & 0,258 & $-0,0008$ & 0,001 \\
K-9 & 0,250 & $-0,0008$ & 0,001 \\
\hline
\end{tabular}

Fonte: Elaborado pelos autores.

Nota: a Fórmula do I de Moran esperado é descrita como $-1 / n-1$.

A relação positiva do capital humano rural entre os municípios vizinhos ocorre por conta do spillover de conhecimento como explicado por Ramos, Suriñach e Artís (2010). O capital humano é importante para o aumento da produtividade agrícola e do crescimento regional, diante disso, possivelmente o aumento deste elemento em um município terá efeito positivo no município vizinho.

$\mathrm{Na}$ análise global bivariada verifica-se que a variável $\mathrm{CH}$ Rural é positivamente correlacionada com todas as outras variavéis como apresentada pela 
Figura 2. A maior correlação acontece entre o capital humano rural e a produtividade do soja, enquanto a menor correlação ocorre com a produtividade do milho. Além da produtividade do milho, a produtividade do trigo também possui associação espacial menor que a associação espacial das médias das produtividades das culturas. Portanto, pode-se afirmar que a associação espacial entre capital humano rural e as três principais culturas da região Sul é fortemente influenciada pela produtividade do soja.

Figura 2 - I de Moran global multivariado.

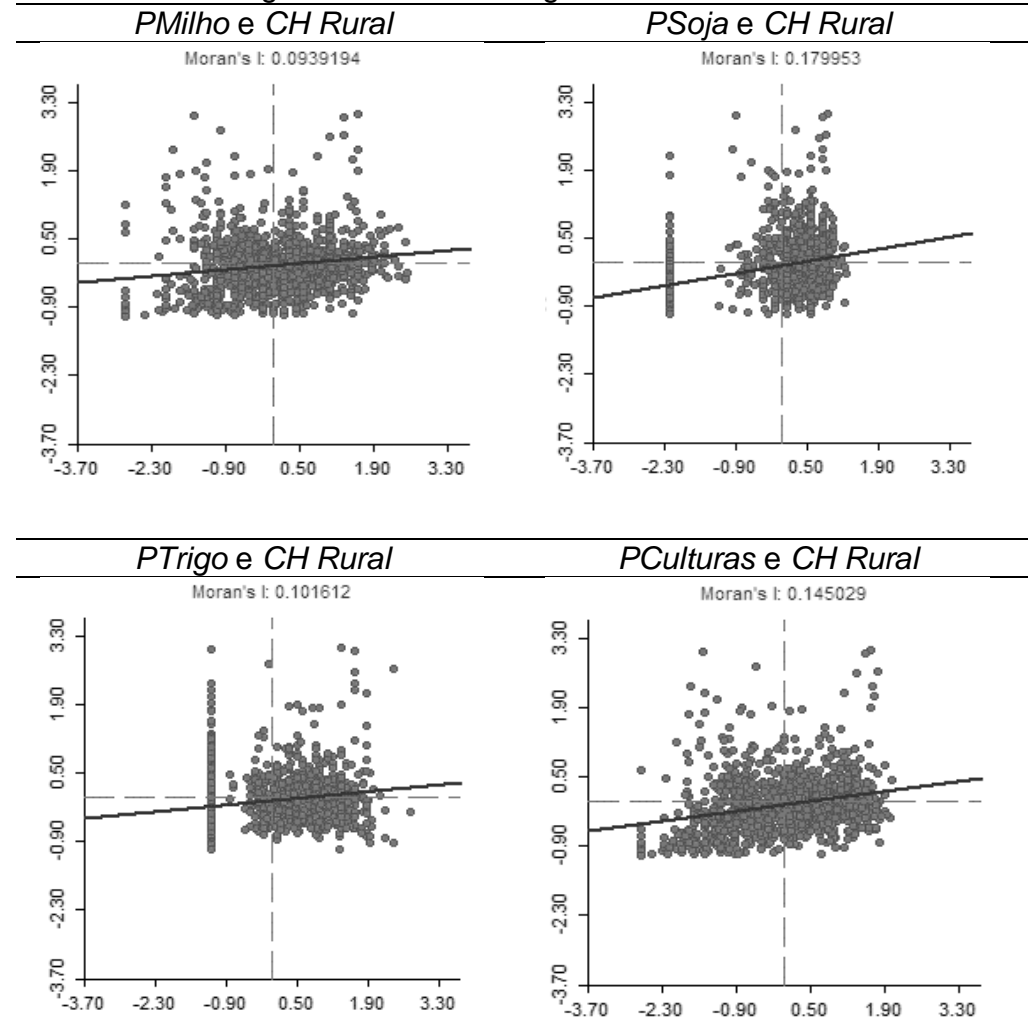

Fonte: Elaborado pelos autores.

Na análise LISA é possível captar efeitos locais que não são possíveis captar na análise global, na Figura 3 observa-se que no litoral o cluster predominantes é o Baixo-Baixo, isto ocorre porque nesta região a razão entre zona rural e urbana é menor, portanto, os municípios presentes neste cluster possuem baixa produtividade agrícola e são rodeados por municípios com baixo nível de capital humano agrícola.

O cluster Baixo-Alto está presente no sul do Rio Grande do Sul em todas as análises locais multivariadas. Nesta região os municípios que possuem baixa produtividade agrícola são rodeados por municípios que possuem alto nível de capital humano agrícola. O bioma predominante neste local é o Pampa ideal para a produção de celulose que apesar de estar perdendo espaço para o cultivo de produtos agrícolas 
conforme explicado por Echer et al. (2015), ainda lida com a situação de baixa produtividade nestes produtos comparados ao norte do estado.

Figura 3 - LISA multivariada
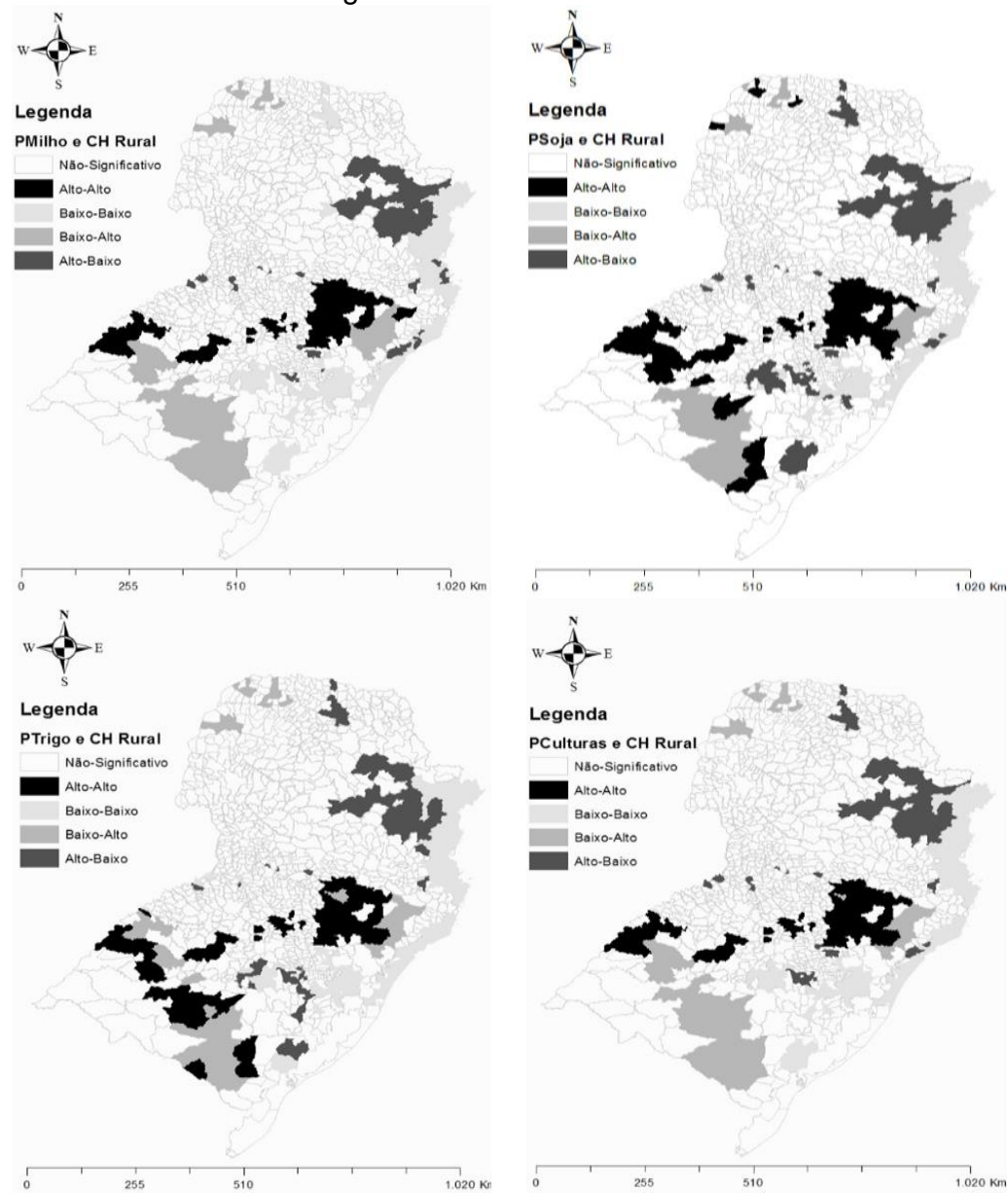

Fonte: Elaborado pelos autores.

No sentido oposto, ocorre o cluster Alto-Baixo no leste paranaense, os municípios que estão presentes neste cluster possuem alta produtividade agrícola e são rodeados por municípios com baixo nível de capital humano rural. A alta produtividade do cultivo de soja e milho neste local já existia desde o ano 2000 de acordo com os resultados encontrados por Felema et al. (2016).

O cluster Alto-Alto está presente majoritariamente no estado do Rio Grande do Sul. Para o cultivar milho, o cluster ocorre no noroeste e no nordeste do estado. Sendo que, nas culturas de soja e trigo, os clusters estão presentes também em alguns pontos do centro-sul do estado. Os municípios presentes nestes clusters possuem alta produtividade agrícola e são rodeados de municípios com alto nível de capital humano rural. 


\section{CONCLUSÃO}

O efeito aumento na produtividade surge porque o aumento na educação pode melhorar a qualidade do conjunto de trabalho e pode ser definido como a capacidade de produzir mais utilizando as mesmas condições de solo, tecnologia, clima e insumos. A melhora na educação e capacitação também melhora a capacidade de adquirir e analisar informações que levem o produtor rural a ser mais eficiente na sua tomada de decisões, tendo capacidade de ajustar os seus planos de produção com uma amplitude de acesso maior as ferramentas de gerenciamento de risco de produção, de preço e outras possíveis causalidades que possam vir a afetar as lavouras.

De acordo com a análise global, o capital humano em zonas rurais é fundamental para o aumento da produtividade agrícola e do crescimento regional, diante disso, o aumento deste elemento em um município terá efeito positivo no município vizinho.

Os resultados dessa pesquisa demonstraram que a maior correlação acontece entre o capital humano rural e a produtividade do soja, enquanto a menor correlação ocorre com a produtividade do milho. Além da produtividade do milho, a produtividade do trigo também possui associação espacial menor que a associação espacial das médias das produtividades das culturas. Portanto, pode-se afirmar que a associação espacial entre capital humano rural e as três principais culturas da região Sul é fortemente influenciada pela produtividade do soja, visto que ela se sobressai no extremo noroeste do Paraná e no extremo sul do Rio Grande do Sul, enquanto a produtividade do milho e do trigo não possuem este comportamento.

Portanto, como apresentando em Lockheed et al. (1980), os efeitos de anos de estudo e/ou capacitação para os produtores agrícolas geram impactos positivos sobre a produtividade agrícola resguardadas variáveis de controle não observados. O resultado ocorre por conta do spillover de conhecimento como explicado por Ramos, Suriñach e Artís (2010). O capital humano é importante para o aumento da produtividade agrícola e do crescimento regional, diante disso o aumento deste elemento em um munic[opio terá efeito positivo no município vizinho.

Contudo, ressalta-se um dos resultados contrários a esta hipótese encontrado na análise LISA, no sul do Rio Grande do Sul o cluster Baixo-Alto está presente em todas as análises locais multivariadas, nesta região os municípios que possuem baixa produtividade agrícola são rodeados por municípios que possuem alto nível de capital humano agrícola, o que pode ser é explicado parcialmente pela aptidão de seu bioma para outros cultivos.

\section{REFERÊNCIAS}

ALMEIDA, E. S.; PEROBELLI, F. S.; FERREIRA, P. G. C. Existe convergência espacial da produtividade agrícola no Brasil? Revista de Economia e Sociologia Rural, v.46, n.1, p.31-52, 2008.

ALMEIDA, E. Econometria espacial. Campinas, São Paulo, Alínea, 2012.

ANSELIN, L. Local Indicators of Spatial Association - LISA. Geographical analysis, v.27, n.2, p.93-115, 1995.

ARAUJO, P. H. C. Eventos climáticos extremos: os efeitos dos fenômenos El Niño e La Niña sobre a produtividade agrícola das regiões Nordeste e Sul do Brasil. Dissertação - Universidade Federal de Viçosa, 2012. 
BECKER, G. S; MURPHY, K. M. The Division of Labor, Coordination Costs, and Knowledge. The Quarterly Journal of Economics, v.107, n.4, p.1137-1160, 1992.

BINSWANGER, H. Agricultural mechanization: a comparative historical perspective. The World Bank Research Observer, v.1, n.1, p. 27-56, 1986.

BLAUG, M. The methodology for economics: or how economists explain. Cambridge University Press, New York, 1992.

CABRAL, A.; SILVA, C. L. M.; SILVA, L. F. L. Teoria do capital humano, educação, desenvolvimento econômico e suas implicações na formação de professores. Revista Principia, n.32, 2016.

ECHER, R.; CRUZ, J. A. W.; ESTRELA, C. C.; MOREIRA, M.; GRAVATO, F. Usos da terra e ameaças para a conservação da biodiversidade no bioma Pampa, Rio Grande do Sul. Revista Thema, v.12, n.2, p. 4-13, 2016.

FELEMA, J.; MEDEIROS, E. R.; FERREIRA, C. R.; CAMARA, M. R. G.; NASCIMENTO, S. P. Um estudo da produtividade do feijão, do milho e da soja na agricultura paranaense, nos anos de 2000 e 2010: uma análise espacial. Ensaios FEE, v.36, n.4, p. 817-842, 2016

FERREIRA, S. G; VELOSO, F. A. A escassez da educação. In: GIAMBIAGI, F.; E VILLELA, A. Economia Brasileira Contemporânea (1945-2004). Elsevier, p.378$399,2005$.

HUFFMAN, W. E. Modernizing agriculture: a continuing process. Daedalus, v.127, n.4, p. 159-86, 1998.

HUFFMAN, W. E. Human capital: education and agriculture. Handbook of agricultural economics, p. 333-381, 2001.

HUFFMAN, W. E. EVENSON, R. E. Structural and productivity change in US agriculture, 1950-1982. Agricultural Economics, v.24, n.2, p. 127-147, 2001.

INSTITUTO BRASILEIRO DE GEOGRAFIA E ESTATÍSTICA. Censo Agropecuário, 2017. Disponível em: https://censos.ibge.gov.br/agro/2017. Acesso em: 28 out. 2019.

INSTITUTO BRASILEIRO DE GEOGRAFIA E ESTATÍSTICA. Levantamento sistemático da produção agrícola, 2017. Disponível em: https://sidra.ibge.gov.br/home/lspa/brasil. Acesso em: 28 out. 2019.

INSTITUTO BRASILEIRO DE GEOGRAFIA E ESTATÍSTICA. Pesquisa Agrícola Municipal, 2017. Disponível em: https://sidra.ibge.gov.br/pesquisa/pam/tabelas. Acesso em: 28 out. 2019.

KUMAR, A; KUMAR, V. A. Pedagogy in higher education of agriculture. ProcediaSocial and Behavioral Sciences, v.152, p.89-93, 2014.

LOCKHEED, M. E; JAMISON, D. T; LAU, L. J. Farmer Education and Farm Efficiency: A Survey. Economic Development and Cultural Change, v.29, n.1, p.37-76, 1980. 
MARQUES, P. V.; MELLO, P. C.; MARTINES, J. G. Mercados Futuros e de Opções Agropecuárias. Piracicaba, São Paulo, Departamento de Economia, Administração e Sociologia da Esalq/USP, 2006.

MELLOR, J. W. The process of agricultural development in low-income countries. American Journal of Agricultural Economics, v. 45, n. 3, p.448-449, 1963.

MENDES, C. M.; PEREIRA, R. S. Educação e produtividade rural: reflexões conceituais para uma agenda de pesquisa, 2009.

MONTEIRO, W. F. A metodologia neoclássica da teoria do capital humano: Uma análise sobre Theodore Schultz e Gary Becker. Revista de Economia do CentroOeste, v.2, n.1, p.40-56, 2016.

PATRICK, G. F; KEHRBERG, E. W. Costs and returns of education in five agricultural areas of eastern Brazil. American Journal of Agricultural Economics, v. 55, n.3, p.657-658, 1974.

PONTES, T. T. S; MAIA, S. F. Precificação de opções sobre contratos futuros de Boi Gordo na BM\&FBovespa. Economia Aplicada, v.21, n.4, 2017, p.737-760.

RAMOS, R.; SURIÑACH, J.; ARTÍS, M. Human capital spillovers, productivity and regional convergence in Spain. Regional Science, v.89, n.2, p.435-447, 2010.

SCHULTZ, T. W. Investment in human capital. The American economic review, v.51, n.1, p.1-17, 1961.

SCHULTZ, T. W. The value of children: an economic perspective. Journal of Political Economy, v.81, n.2, p.2-13, 1973.

SCHULTZ, T. W. The value of the ability to deal with disequilibria. Journal of Economic Literature, v.13, n.3, p. 827- 846, 1975.

STRECK, N. A.; ALBERTO, C. M. Estudo numérico do impacto da mudança climática sobre o rendimento de trigo, soja e milho. Pesquisa Agropecuária Brasileira, v.41, n.09, 2006.

VICENTE, J. R.; ANEFALOS, L. C.; CASER, D. V. Influência de capital humano, insumos modernos e recursos naturais na produtividade agrícola. Região e Espaço no Desenvolvimento Agrícola Brasileiro, 2003. 